REVIEWS

\title{
Damage control in penetrating carotid artery trauma: changing a 100-year paradigm
}

\section{Control de daños en el trauma penetrante de la arteria carótida: cambiando un paradigma de 100 años}

\author{
José Julián Serna ${ }^{1,2,3,4}$ Carlos A. Ordoñez ${ }^{1,2,3}$ Michael W. Parra $^{5}$ (iD Edgar Folleco $^{6}$ \\ Yaset Caicedo ${ }^{7}$ (D) Alberto Rosero ${ }^{6}$ (D)Fernando Velásquez ${ }^{8}$ (D) Carlos Serna ${ }^{2}$ (D) Alexander \\ Salcedo ${ }^{1,2,3,4}$ Alberto García 1,2,3 (iD) Adolfo González-Hadad 2,4,9 (D) Mario Alain Herrera ${ }^{2,4}$ (D) \\ Luis Fernando Pino ${ }^{2,4}$ (D) Maria Josefa Franco ${ }^{1}$ (D) Fernando Rodríguez-Holguín ${ }^{1}$ (D) \\ ordonezcarlosa@gmail.com, carlos.ordonez@fvl.org.co
}

1 Fundación Valle del Lili, Department of Surgery, Division of Trauma and Acute Care Surgery, Cali, Colombia.2 Universidad del Valle, Facultad de Salud, Escuela de Medicina, Department of Surgery, Division of Trauma and Acute Care Surgery. Cali, Colombia.3 Universidad Icesi, Cali, Colombia. 4 Hospital Universitario del Valle, Department of Surgery, Division of Trauma and Acute Care Surgery, Cali, Colombia.5 Broward General Level I Trauma Center, Department of Trauma Critical Care, Fort Lauderdale FL , USA -6 Fundación Valle del Lili, Department of Radiology, Division of Neuroradiology, Cali, Colombia. 7. Fundación Valle del Lili, Centro de Investigaciones Clínicas (CIC), Cali, Colombia. 8 Fundación Valle del Lili, Department of Neurosurgery, Cali, Colombia.9 Centro Médico Imbanaco

\section{Abstract}

Carotid artery trauma carries a high risk of neurological sequelae and death. Surgical management of these injuries has been controversial because it entails deciding between repair or ligation of the vessel, for which there is still no true consensus either way. This article proposes a new management strategy for carotid artery injuries based on the principles of damage control surgery which include endovascular and/or traditional open repair techniques. The decision to operate immediately or to perform further imaging studies will depend on the patient's hemodynamic status. If the patient presents with massive bleeding, an expanding neck hematoma or refractory hypovolemic shock, urgent surgical intervention is indicated. An altered mental status upon arrival is a potentially poor prognosis marker and should be taken into account in the therapeutic decision-making. We describe a step-by-step algorithmic approach to these injuries, including open and endovascular techniques. In addition, conservative non-operative management has also been included as a potentially viable strategy in selected patients, which avoids unnecessary surgery in many cases. 
Palabras clave:

Lesiones de cuello, lesiones del sistema vascular, lesiones de la arteria carótida, arteria carótida, atención de soporte vital avanzado para traumatismos, procedimientos endovasculares, stents, angioplastia.

Copyright: @ 2021 Universidad del Valle (c) (1) $(-)$

Conflicts of interest:

The authors declare that they have no conflict of interest.

\section{Acknowledgements:}

We would like to extend our gratitude to the anatomical illustrator Fabian R. Cabrera P., Professor of the Design Department of the Integrated Arts Faculty, for the illustrations and cover design. We also acknowledge Linda M. Gallego for her contributions in the drafting of this manuscript.

Corresponding author:

Carlos A. Ordonez, MD, FACS. Division of Trauma and Acute Care Surgery, Department of Surgery. Fundación Valle del Lili. Cali, Colombia; Division of Trauma and Acute Care Surgery, Department of Surgery, Universidad del Valle, Cali, Colombia; Universidad Icesi, Cali, Colombia. Email: ordonezcarlosa@gmail.com, carlos.ordonez@fvl.org.co

\section{Resumen}

El trauma de la arteria carótida tiene una alta probabilidad de muerte y de secuelas neurológicas. El manejo quirúrgico es objeto de controversia porque se tiene que decidir entre reparar la arteria carótida o ligarla, para lo cual aún no existe un consenso. El objetivo de este artículo es proponer una nueva estrategia de manejo para el trauma de la arteria carótida con los principios de la cirugía de control de daños y el uso de técnicas como el reparo endovascular o el manejo conservador. La decisión de operar el paciente inmediatamente o realizar estudios imagenológicos dependerá del estado hemodinámico del paciente. Si el paciente presenta sangrado masivo, hematoma expansivo o choque hipovolémico refractario, una intervención quirúrgica urgente esta indicada. Un déficit del estado neurológico al ingreso es un marcador de mal pronóstico en estos casos e influye en la toma de decisiones. Se describe el paso a paso del reparo vascular abierto y se incluye las estrategias de manejo tanto endovasculares como abiertas. Adicionalmente, el manejo conservador también ha sido incluido como una estrategia viable en pacientes seleccionados, evitando cirugías innecesarias.

\section{Remark}

\section{1) Why was this study conducted?}

The aim of this article is to propose a new management strategy for carotid artery injuries based on the principles of damage control surgery which include endovascular and/or traditional open repair techniques.

\section{2) What were the most relevant results of the study?}

If the patient presents with massive bleeding, an expanding neck hematoma or refractory hypovolemic shock, then urgent surgical intervention is indicated. An altered mental status upon arrival is a potential poor prognosis marker and should be considered in the therapeutic decision making. We describe a step by step algorithmic approach to these injuries which include both open and endovascular techniques. In addition, conservative non-operative management has also been included as a potential viable strategy in selected patients, which in turn avoids unnecessary surgery in many cases.

\section{3) What do these results contribute?}

Open surgical exploration has been the prevailing paradigm in the management of penetrating carotid trauma. However, endovascular management can be applied in selected patients also following damage control principles and performing less invasive interventions to repair and/or control vascular injuries. 


\section{Introduction}

Carotid artery trauma carries a high risk of neurological sequelae and death ${ }^{1}$. Carotid artery injuries occur in approximately $3-11 \%$ of cases of penetrating neck trauma ${ }^{1,2}$. Carotid vascular trauma varies in the spectrum from life-threatening to subtle injuries, but all can generate neurological sequelae ${ }^{3}$. Therefore, the surgeon must decide expeditiously on the appropriate management strategy to optimize the outcome, especially in hemodynamically unstable patients ${ }^{4,5}$. The traditional surgical strategies for severe carotid injuries have been limited to primary open vascular repair or ligation of the vessel ${ }^{6,8}$. However, new imaging and endovascular technologies have provided opportunities for earlier diagnosis and alternative treatment modalities ${ }^{7,9}$. This article proposes a new management algorithm for penetrating carotid artery trauma based on the principles of damage control surgery, including non-operative, endovascular, and traditional open repair techniques.

This article is a consensus that synthesizes the experience earned during the past 30 years in trauma management, general surgery and critical care acquired by the Trauma and Emergency Surgery (CTE) group from Cali, Colombia which is made up of experts from the Hospital Universitario del Valle "Evaristo García”, the Hospital Universitario Fundación Valle del Lili, the Universidad del Valle and Universidad Icesi, and the collaboration of national and international specialists from the Asociación Colombiana de Cirugía and the Pan-American Trauma Society.

\section{Epidemiology}

The overall prevalence of carotid injuries is between 6 to $11 \%^{1,2}$. The most commonly involved anatomical segments are the common carotid and the internal carotid arteries. Previously published case series have reported that approximately half the patients with these injuries are managed non-operatively ${ }^{8}$. Of the patients that underwent open surgical management, only $20 \%$ required vessel ligation due to massive hemorrhage ${ }^{1,6,10-13}$. However, endovascular management has evolved, especially during this last decade. A recent analysis of the National Trauma Data Bank reported that $12 \%$ of patients undergoing surgical management of carotid artery injuries were treated via endovascular techniques with no significant difference in mortality and/or complications compared to the traditional open surgical approach ${ }^{14}$.

\section{Initial Approach}

Initial efforts should be directed towards bleeding control and physiologic stabilization of the patient according to the Advanced Trauma Life Support (ATLS) guidelines and damage control surgery principles ${ }^{15,16}$. The decision to operate immediately or to perform imaging studies will depend on the patient's hemodynamic status upon admission. If the patient presents with massive bleeding, expansive hematoma or hypovolemic shock that persists after resuscitation with blood products, urgent surgical intervention is required. On the other hand, the patient with normal vital signs, a stable hematoma, or hemodynamic instability that responds to resuscitation should be evaluated through complementary studies. An impaired neurological status upon admission is a marker for poor prognosis and should influence intra-operative decisionmaking ${ }^{14}$ (Table 1).

Table 1. Neurologic Criteria of Poor Prognosis in Penetrating Carotid Trauma.

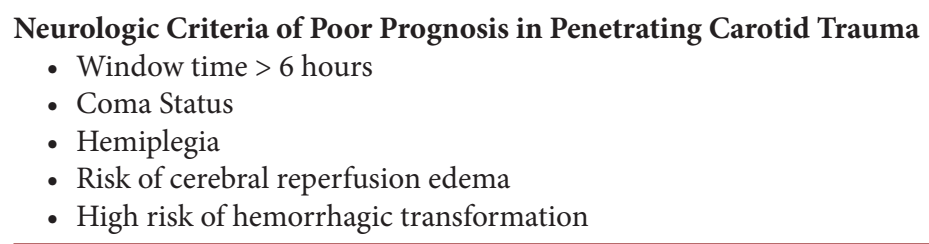


Table 2. AAST Classification of Cervical Vascular Trauma ${ }^{16}$.

\begin{tabular}{cl}
\hline Grade & Description \\
\hline I & Thyroid vein Common Facial Vein \\
& External Jugular Vein \\
& Unnominated arterial/venous branches \\
II & Arterial branches of the external carotid (ascending pharyngeal artery, upper thyroid, \\
& lingual, maxillary, facial, occipital, posterior auricular) \\
& Thyrocervical trunk or primary branches \\
& Internal Jugular Vein \\
& External Carotid Artery \\
III & Subclavian Vein \\
& Vertebral Artery \\
& Common Carotid Artery \\
IV & Subclavian Artery \\
V & Internal Carotid Artery (extracranial portion) \\
*Increase one grade for multiple grade III or IV injuries involving more than 50\% vessel circumference. Decrease one grade for less than $25 \%$ vessel \\
circumference disruption for grade IV or V.
\end{tabular}

Table 3. Denver Grading Scale for Blunt Carotid and Vertebral Artery Injury ${ }^{17}$

\begin{tabular}{cl}
\hline Grade & Description \\
\hline I & Luminal irregularity or dissection with $<25 \%$ luminal narrowing \\
II & Dissection or intramural hematoma with $>25 \%$ luminal narrowing Intraluminal \\
III & Pseudoaneurysm \\
IV & Occlusion \\
V & Transection with free extravasation \\
\hline
\end{tabular}

Penetrating carotid trauma does not have an independent grading system, but it is included in the American Association for the Surgery of Trauma (AAST) classification for cervical vascular trauma (Table 2) ${ }^{17}$. It has been customary to use the blunt trauma classification of these injuries in cases of penetrating trauma. However, our experience is that these two mechanisms of injuries are widely different in their pathophysiology and their management ${ }^{18}$ (Table 3 ) .

\section{Treatment}

The management of carotid artery injuries has evolved over the years. Ligation used to be the only surgical option and today, the carotid artery is repaired with a variety of open and/or endovascular techniques. Open surgical options include temporary vascular shunts, primary repair, patch angioplasty, external carotid artery transposition and ligation. Endovascular surgical options include the placement of covered stents and/or occlusion of injured vessels ${ }^{19}$.

\section{Endovascular Management}

Endovascular management has risen during the last two decades, especially using hybrid therapies for post-traumatic pseudoaneurysms and carotid artery dissections ${ }^{14,20,21}$. We recently published a case series of 20 patients with penetrating carotid injuries managed from January 2018 until December $2019^{22}$. Gunshot wounds was the most common mechanism of injury. Open surgical management was performed in 3 patients, endovascular management in 9 ( 7 required covered stent and two required embolization) and non-operative management in 8 . Four patients died ( 2 from stroke) and 11 were discharged home without neurologic sequelae 22 (Tables 4 and 5).

We were able to determine potential candidates for endovascular management as those who were hemodynamically stable or transient responders to initial damage control resuscitation upon arrival and in whom temporary bleeding was achieved in the Emergency Room (ER). Also, a quick neurological exam should be performed in the ER as an indirect baseline assessment of the patency of the patient's Circle of Willis. If this type of examination is not achievable, then a computed tomographic angiography (CTA) of the neck and brain is recommended.

CTA should be used as the basis for classifying the extent of the injury, which includes partial 
or complete loss of vascular continuity, pseudoaneurysm and/or intimal flap, rather than using the traditional AAST blunt trauma grading system. If vessel occlusion with a patent Circle of Willis is identified, then conservative non-operative management is recommended along with antiplatelet/anticoagulant therapy to reduce the risk of cerebral embolism and subsequent stroke. If patency is not detected, then endovascular stent placement should be considered to restore vascular perfusion. Pseudoaneurysms of less than $5 \mathrm{~mm}$ should be managed nonoperatively, while those greater than $5 \mathrm{~mm}$ will require repair. Formal angiography is recom-

Table 4. Clinical Characteristics

\begin{tabular}{|c|c|}
\hline & Carotid Artery Injury $(n=20)$ \\
\hline \multicolumn{2}{|l|}{ Gender } \\
\hline Male & 18 \\
\hline Age, years, median (IQR) & $34(25-42)$ \\
\hline \multicolumn{2}{|l|}{ Type of Trauma } \\
\hline Penetrating & 18 \\
\hline Stabbing wounds & $2 / 18$ \\
\hline Gunshot wounds & $16 / 18$ \\
\hline Blunt, n (\%) & 2 \\
\hline \multicolumn{2}{|l|}{ Status on Admission } \\
\hline HR, median (IQR) & $97(70-117)$ \\
\hline GCS, median (IQR) & $14(9-15)$ \\
\hline SBP, median (IQR) & $117(80-125)$ \\
\hline Shock Index, median (IQR) & $0.9(0.5-1.5)$ \\
\hline Paresis & 8 \\
\hline Active bleeding & 13 \\
\hline Expansive hematoma & 8 \\
\hline Stable hematoma & 11 \\
\hline Transfusion & 10 \\
\hline Traumatic Brain Injury & 19 \\
\hline \multicolumn{2}{|l|}{ Surgical Approach } \\
\hline Raffia & 1 \\
\hline Saphenous Graft & 1 \\
\hline Ligature & 1 \\
\hline No & 17 \\
\hline \multicolumn{2}{|l|}{ Arteriography } \\
\hline Diagnostic & 6 \\
\hline Therapeutic & 9 \\
\hline No & 5 \\
\hline \multicolumn{2}{|l|}{ Endovascular Management } \\
\hline Diagnostic & 6 \\
\hline Embolisation & 2 \\
\hline Stent & 7 \\
\hline No & 5 \\
\hline \multicolumn{2}{|l|}{ Carotid Portion } \\
\hline Common & 5 \\
\hline External & 2 \\
\hline Internal & 13 \\
\hline \multicolumn{2}{|l|}{ Type of Injury } \\
\hline Dissection $<30 \%$ & 2 \\
\hline Dissection $>30 \%$ & 1 \\
\hline Pseudoaneurysm & 7 \\
\hline Rupture & 3 \\
\hline Amputation & 7 \\
\hline Conservative Management & 8 \\
\hline \multicolumn{2}{|c|}{ Antiaggregation / Anticoagulation Therapy } \\
\hline No & 5 \\
\hline Antiaggregation & 7 \\
\hline Anticoagulation & 1 \\
\hline Combined & 7 \\
\hline \multicolumn{2}{|c|}{ Neurological Impairment at Discharge } \\
\hline None & 11 \\
\hline Minor & 4 \\
\hline Major & 5 \\
\hline \multicolumn{2}{|l|}{ Clinical Outcomes } \\
\hline Hospital stay, days, median (IQR) & $5(5-14)$ \\
\hline Mortality & 4 \\
\hline
\end{tabular}


Table 5. Non-Operative Management $(n=7)$

\begin{tabular}{|c|c|c|c|c|c|c|c|c|c|c|}
\hline Sex & Age (years) & $\begin{array}{c}\text { Admission BP } \\
(\mathrm{mm} \mathrm{Hg})\end{array}$ & $\begin{array}{l}\text { Admission } \\
\text { GCS }\end{array}$ & Arteriography & $\begin{array}{c}\text { Anatomical } \\
\text { y Portion of the } \\
\text { Carotid Artery }\end{array}$ & Type of Injury & Other Injuries & $\begin{array}{c}\text { Neurological } \\
\text { Deficit }\end{array}$ & $\begin{array}{l}\text { Hospital Stay } \\
\text { (days) }\end{array}$ & Death \\
\hline $\mathrm{F}$ & 25 & 140 & 14 & Yes & External & Amputation & Facial & No & 3 & No \\
\hline $\mathrm{M}$ & 43 & 120 & 14 & Yes & Internal & Dissection $<30$ & Mandibular & No & 10 & No \\
\hline $\mathrm{M}$ & 51 & 70 & 8 & Yes & External & Amputation & Vertebral & Major & 28 & No \\
\hline $\mathrm{M}$ & 59 & 80 & 7 & No & Internal & Amputation & Severe TBI & Major & 4 & Yes \\
\hline $\mathrm{F}$ & 39 & 135 & 8 & Yes & Internal & Amputation & Petrous Fracture & No & 15 & No \\
\hline $\mathrm{M}$ & 53 & 157 & 11 & No & Common & Amputation & Facial & Major & 5 & Yes \\
\hline $\mathrm{M}$ & 22 & 126 & 15 & Yes & Internal & Dissection $<30$ & Facial & Minor & 17 & No \\
\hline
\end{tabular}

BP: Blood Pressure. GCS: Glasgow Coma Scale. TBI: Traumatic Brain Injury.

mended when doubt persists on the extent and type of injury after a CTA and in those patients with persistent subclinical cervical or cerebral bleeding. Patients with intramural thrombus, intimal flap defects and/or vessel dissections with intact distal blood flow are candidates for non-operative management with or without antiplatelet/ anticoagulant therapy depending on each individuals' comorbidities and risk assessment.

Major vessel lacerations without complete disruption or pseudoaneurysms larger than $5 \mathrm{~mm}$ are candidates for endovascular stent management. In cases in which the vessel is completely thrombosed or a larger injury with an inherently high risk of re-bleeding that is not amenable to stent placement, the contralateral blood flow should be evaluated along with the possibility of reinforcing the occlusion with endovascular coil embolization. All of these patients will require close neurologic monitoring in the intensive care unit (ICU) postoperatively.

\section{Non-operative management}

Non-operative management is the therapy of choice in well-selected cases. The aim is to avoid unnecessary morbidity. Indications include: patients with signs of cerebral ischemia but are not candidates for endovascular therapy, vessel occlusion with a patent Circle of Willis, those with pseudoaneurysms less than $5 \mathrm{~mm}$ and those who present with a significant neurological deficit and an inherent poor prognosis ${ }^{23,24}$.

\section{Operative management}

The following is a step-by-step management algorithm for hemodynamically unstable patients with hard signs of carotid artery injury:

STEP 1: Control of immediate surgical hemorrhage should be initiated in the Emergency Room (ER) via direct compression. The patient is typed and crossed and the institutions massive transfusion protocol (MTP) is activated. The patient is then transferred to the operating room (OR) ${ }^{25,26}$. The initial surgical approach is via a right or left neck incision according to the injury site. Considering that an expanding hematoma may obscure the anatomical reference of the anterior edge of the sternocleidomastoid muscle, we recommend an imaginary line between the earlobe crease and the sternal notch as a guide for the initial incision.

STEP 2: Proximal and distal control of the injured vessel is of upmost importance:

Carotid Common Artery: If the injury to the vessel is at its origin, then an extension of the incision towards a median sternotomy may be required to achieve proximal control.

External Carotid Artery: Proximal control may require dissection of the bifurcation of the common carotid artery. 

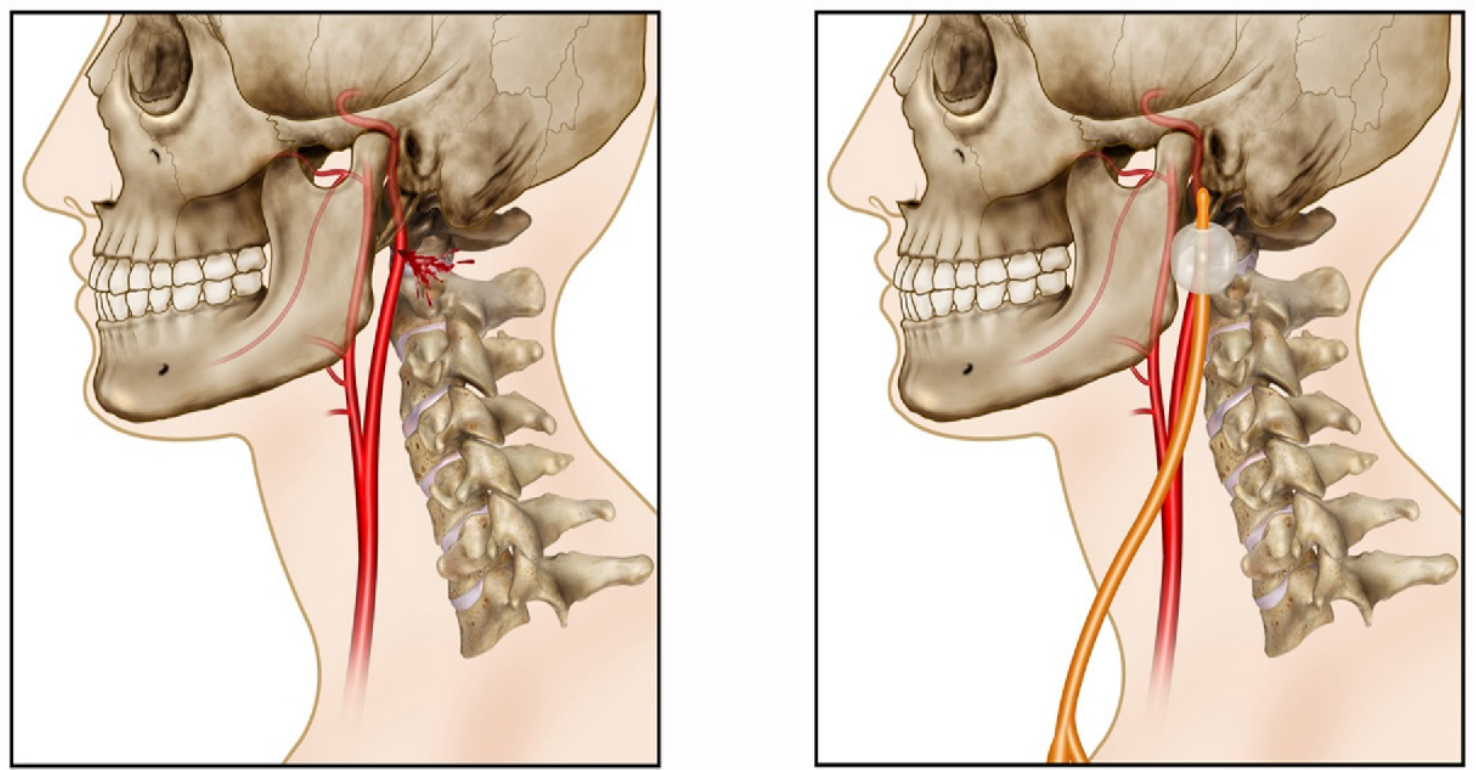

Figure 1. Temporary Hemorrhage Control of the Internal Carotid Artery. A. Distal internal carotid artery injury. B. Maneuver to stop distal internal carotid artery bleeding by placing a Foley catheter into the track of the wound.

Internal Carotid Artery: Only its extra-cranial portion is amenable to surgical repair. Proximal control can be achieved at the level of the common carotid artery or the proximal internal carotid artery. If distal control is technically difficult via your initial incision, then an anterior mandibular dislocation may be necessary to obtain better exposure of the distal vessel. This maneuver can expose approximately $2 \mathrm{~cm}$ more of the distal vessel in most patients. In cases where distal vascular control is still not obtainable, we recommend placing a Foley catheter into the wound and inflating the balloon until hemorrhage control is achieved (Figure 1). Another alternative is placing a Fogarty catheter into the injured vessel and achieving distal control by advancing the catheter beyond the injury site and inflating the balloon ${ }^{19,27}$.

STEP 3: Once hemorrhage control has been achieved, the surgeon must determine the appropriate surgical repair approach of the injury. Suppose the patient has an overall poor prognosis upon arrival (Table 1), absence of distal reflux bleeding from the injured vessel (Figure 2), and/ or an external carotid artery injury associated with hemodynamic instability. In that case, we recommend ligating the vessel as a definitive surgical therapy (Figure 3). Otherwise, we recommended primary repair of the vessel. Common and internal carotid arteries injuries should be repaired using a synthetic [Goretex or PTFE (polytetrafluoroethylene)] interposition graft, rather than an autologous reverse saphenous vein graft which requires a separate incision, prolonged surgical time and is not conducive to damage control management principles (Figure 4).

STEP 4: For distal internal carotid injuries, where hemorrhage control requires Foley or Fogarty catheter balloon placement (Figure 1), we recommend the immediate transfer of the patient to a hybrid or angiography suite for endovascular stent placement (Figure 5).

STEP 5: Surgical field hemostasis should be carefully verified and in cases of ongoing nonsurgical bleeding due to coagulopathy persists, then the wound should be packed, and a negative pressure dressing placed. The patient should then be transferred to the Intensive Care Unit (ICU) to continue with rewarming, correction of coagulopathy and damage control resuscitation ${ }^{28}$. Close neurologic monitoring should be performed in the ICU and a 24 hour follow-up CTA of the head and neck should be done to evaluate arterial blood flow and secondary tissue injury. 

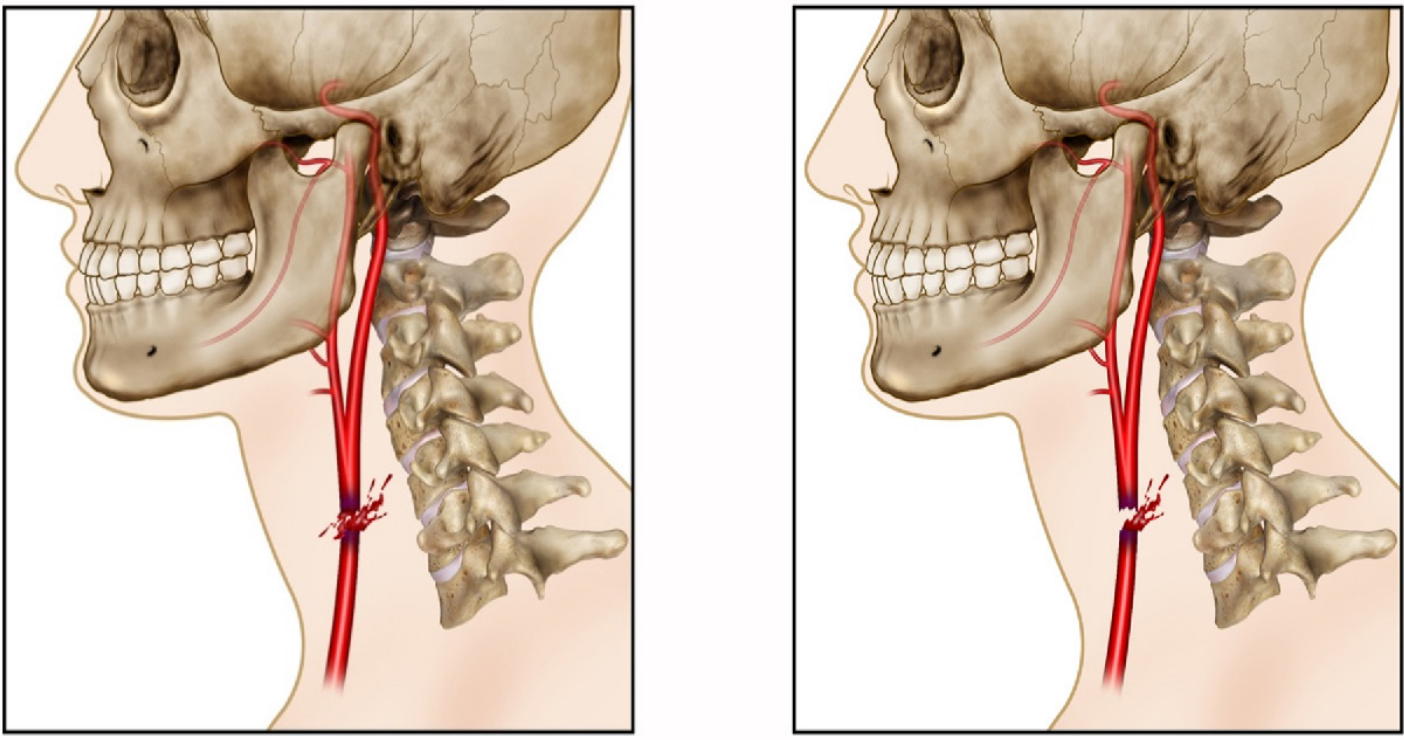

Figure 2. Common Carotid Artery Injury. A. Proximal and distal flow present. B. Proximal flow but no reflux flow from the distal end.
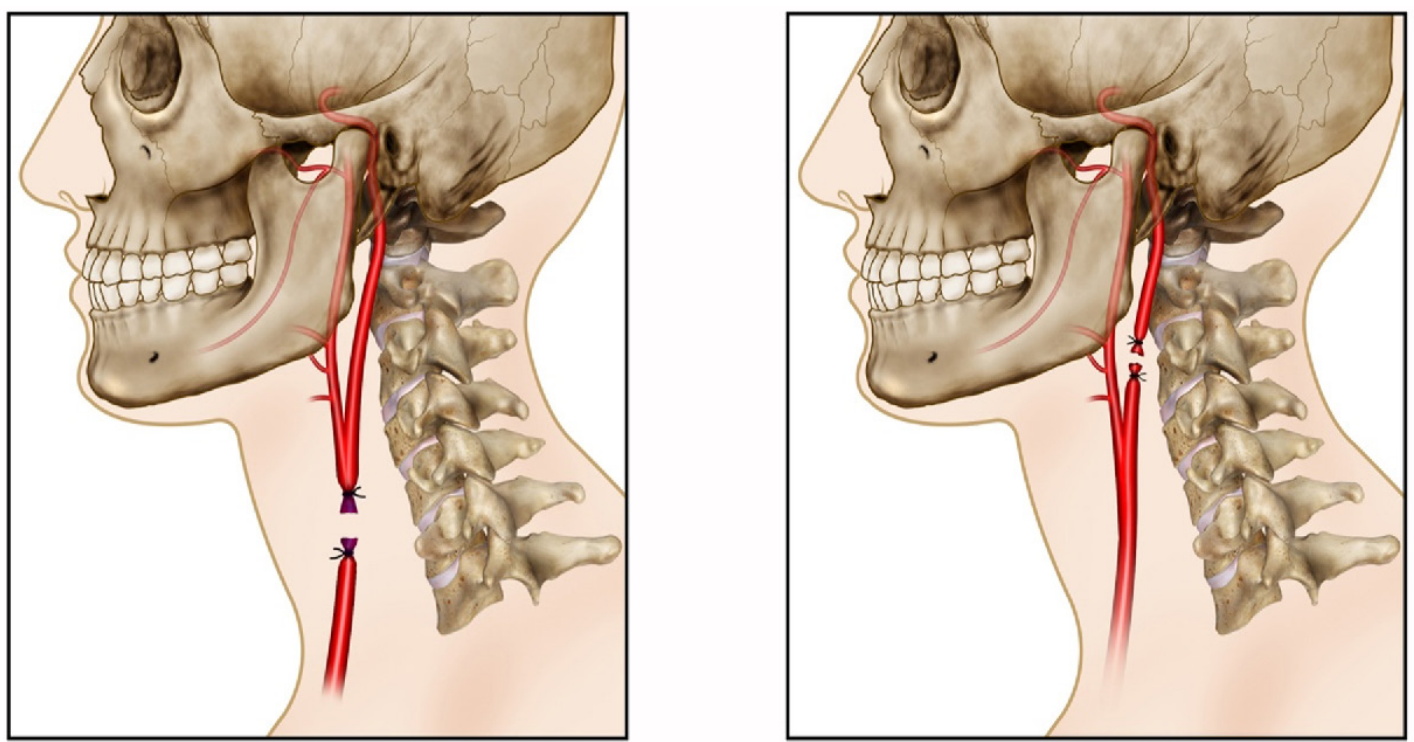

Figure 3. Carotid Artery Ligation. A. Common carotid artery ligation. B. Internal carotid artery ligation.

\section{Discussion}

Studies have shown that protocol-driven management of penetrating neck trauma avoids unnecessary surgical interventions ${ }^{2,29}$. Primary repair, vein patches, Goretex/PTFE or reverse saphenous vein grafts, and even external carotid artery transposition are the most common surgical therapies for managing carotid artery injuries ${ }^{24}$. However, in our series, endovascular management was the most frequently used therapy for penetrating carotid trauma with similar outcomes to those reported who applied open surgical repair ${ }^{22}$. Herrera et al. described the angiographic features of 36 traumatic injuries of the carotid artery during 12 years and found that the injury resulted in a pseudoaneurysm in 24 (66.7\%) of instances and an arteriovenous fistula in $7(19.4 \%)$ which correlate with the findings in our series ${ }^{21}$. During the surgical procedure, the priority is to restore cerebral blood flow. However, in the absence of distal arterial injury reflux 

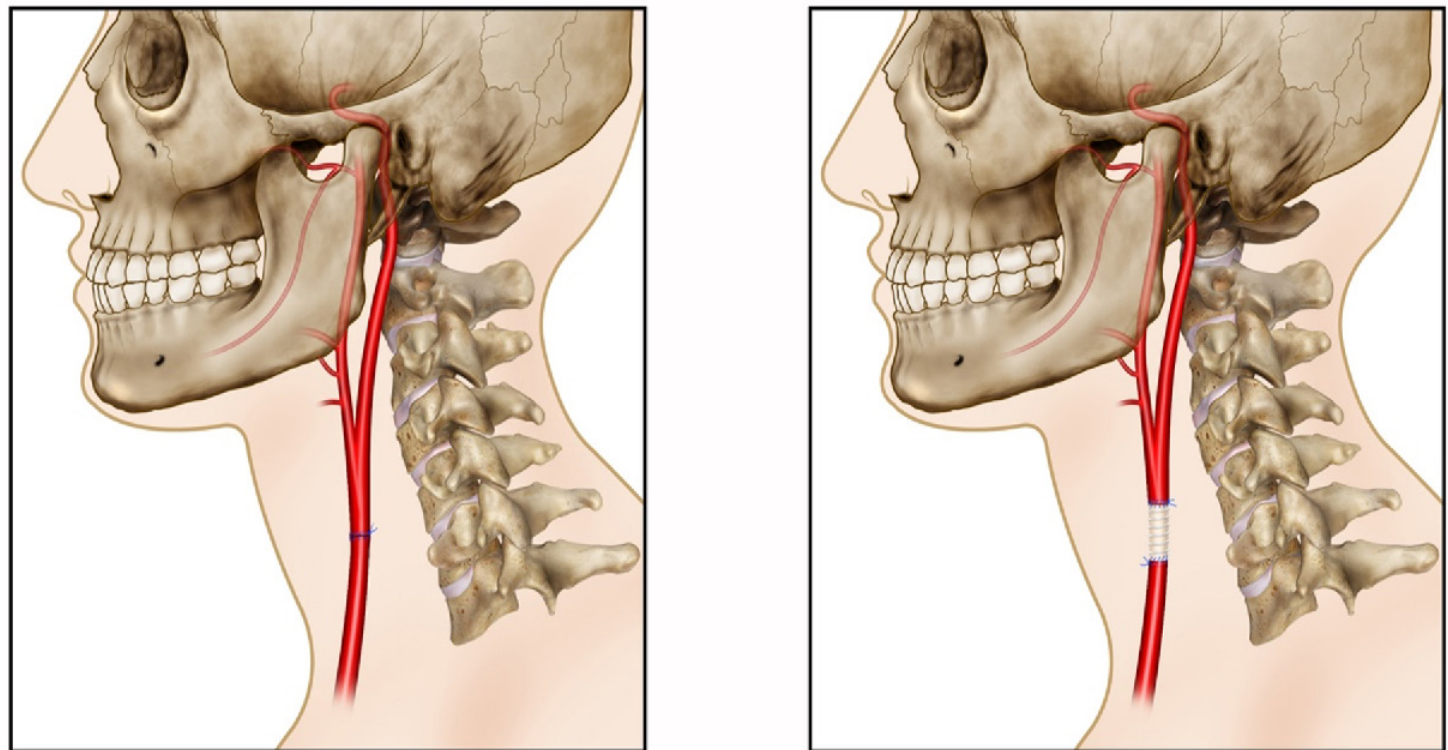

Figure 4. Open Surgical Repair of the Common Carotid Artery . A. Common carotid artery anastomosis. B. PTFE interposition graft.

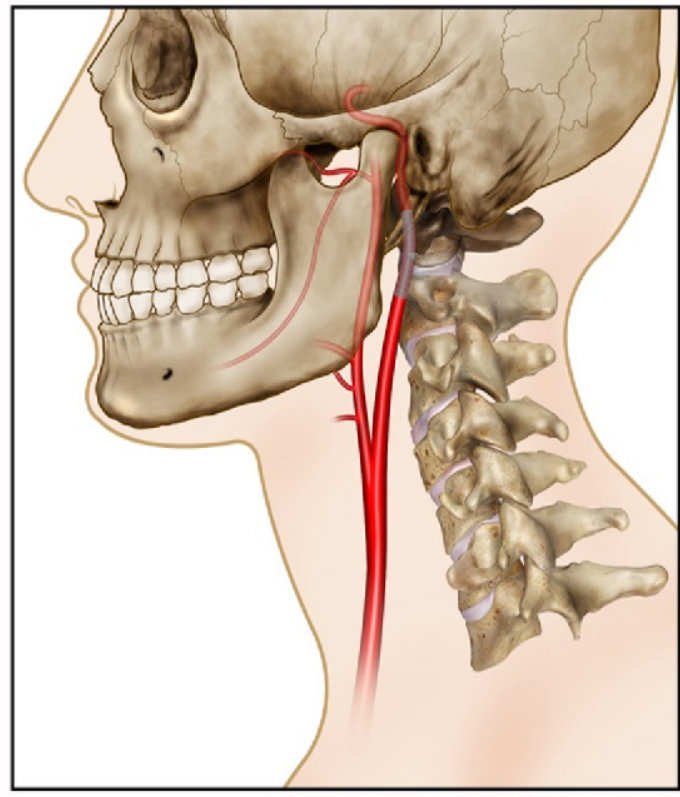

Figure 5. Endovascular Repair of the Internal Carotid Artery. A. Endovascular Stent placement.

bleeding (Figure 2) or in cases of poor overall prognosis upon arrival (Table 1), arterial ligation becomes the strategy of choice to achieve definitive hemorrhage control. White et al. reported that patients who underwent common or internal carotid artery ligation had a mortality rate of $22 \%$ and a stroke rate of $89 \%$ with permanent long-term neurologic sequelae ${ }^{30}$.

There has been insufficient reported data to determine the effectiveness of restoring blood flow in cases of complete traumatic occlusion of the injured carotid vessels. Neurologic recovery has been reported between $42 \%$ and $64 \%$ in those patients managed via primary repair, and $14 \%$ in those in which the vessel was ligated ${ }^{13}$. With these findings in mind, we recommend that at- 
tempts should be made when possible to restore blood flow via an open or endovascular repair. Primary suture repair is the ideal technique for low-grade injuries and interposition grafts for larger ones. Our general recommendation is to use readily available synthetic (PTFE/Goretex) grafts and autologous vein grafts as a secondary option, especially in cases that require the implementation of a damage control strategy ${ }^{31,32}$.

\section{Conclusion}

Open surgical exploration has been the prevailing paradigm in the management of penetrating carotid trauma. However, endovascular management can be applied in selected patients, following damage control principles and performing less invasive interventions to repair and/ or control vascular injuries.

\section{References}

1. Asensio JA, Vu T, Mazzini FN, Herrerias F, Pust GD, Sciarretta J, et al. Penetrating carotid artery: Uncommon complex and lethal injuries. Eur J Trauma Emerg Surg. 2011; 37: 429-37. Doi: 10.1007/s00068-011-0132-3.

2. Demetriades D, Charalambides DLM. Physical examination and selective management in patients with penetrating injuries of the neck. Br J Surg. 1993: 80: 1534-1536.

3. Demetriades D, Salim A, Brown C, Martin M, Rhee P. Neck Injuries. Curr Probl Surg. 2007; 44: 13-85. Doi: 10.1067/j.cpsurg.2006.10.004.

4. Sperry JL, Moore EE, Coimbra R, Croce M, Davis JW, Karmy-Jones R, et al. Western trauma association critical decisions in trauma: Penetrating neck trauma. J. Trauma Acute Care Surg. 2013; 75: 936-40. Doi: 10.1097/TA.0b013e31829e20e3.

5. Hundersmarck D, Reinders FE, de Borst GJ, Leenen LPH, Vriens PWHE, Hietbrink F. Penetrating neck injury in two dutch level 1 trauma centres: the non-existent problem. Eur J Vasc Endovasc Surg. 2019; 58: 455-62. Doi: 10.1016/j.ejvs.2019.04.020

6. Vellimana AK, Lavie J, Chatterjee AR. Endovascular considerations in traumatic injury of the carotid and vertebral arteries. Semin Intervent Radiol. 2021; 38: 53-63. Doi: 10.1055/s-0041-1724008.

7. Weaver FA, Yellin AE, Wagner WH, Brooks SH, Weaver AA, Milford MA. The role of arterial reconstruction in penetrating carotid injuries. Arch Surg. 1988; 123: 1106-11. Doi: 10.1001/archsurg.1988.01400330082013.

8. Liekweg WG, Greenfield LJ. Management of penetrating carotid arterial injury. Ann Surg. 1978; 188: 587-92. Doi: 10.1097/00000658-197811000-00001.

9. Texakalidis P, Karasavvidis T, Giannopoulos S, Tzoumas A, Charisis N, Jabbour P, et al. Endovascular reconstruction of extracranial traumatic internal carotid artery dissections: a systematic review. Neurosurg Rev. 2020; 43: 931-40. Doi: 10.1007/s10143-019-01092-6.

10. Demetriades D, Skalkides J, Sofianos C, Melissas J, Franklin J. Carotid artery injuries: Experience with 124 cases. J Trauma. 1989; 29: 91-4. Doi: 10.1097/00005373-198901000-00019.

11. Unger SW, Tucker WS, Mrdeza MA, Wellons HA, Chandler JG. Carotid arterial trauma. Surgery. 1980; 87 : 477-87. Doi: 10.1097/00006534-198012000-00118.

12. Thal ER, Snyder WH 3rd, Hays RJ, Perry MO. Management of carotid artery injuries. Surgery. 1974; 76: 955-62.

13. Rubio PA, Reul GJ, Beall AC, Jordan GL, Dkbakey ME. Acute carotid artery injury: 25 years' experience. J Trauma. 1974; 14: 967-73. Doi: 10.1097/00005373-197411000-00010. 
14. Blitzer DN, Ottochian M, O'Connor J, Feliciano DV, Morrison JJ, DuBose JJ, et al. Penetrating injury to the carotid artery: characterizing presentation and outcomes from the National Trauma Data Bank. Ann Vasc Surg. 2020: 67: 192-199. Doi: 10.1016/j.avsg.2020.03.013.

15. Advanced trauma life support (ATLS). Student Course Manual. Chicago: American College of Surgeons. 10th Edition; 2018. Doi: 10.1111/j.1365-2044.1993.tb07026.x.

16. Ordoñez CA, Parra MW, Serna JJ, Rodríguez HF, García AF, Salcedo A, et al. Damage control resuscitation : REBOA as the new fourth pillar. Colomb Med (Cali). 2020; 51(4): e4014353. Doi: 10.25100/cm.v51i4.4353.

17. Moore EE, Malangoni MA, Cogbill TH, Peterson NE, Champion HR, Jurkovich GJ, et al. Organ injury scaling VII: Cervical vascular, peripheral vascular, adrenal, penis, testis, and scrotum. J Trauma. 1996; 41: 523-4. Doi: 10.1097/00005373-199609000-00023.

18. Biffl WL, Moore EE, Offner PJ, Brega KE, Franciose RJ, Burch JM. Blunt carotid arterial injuries: implications of a new grading scale. J Trauma. 1999; 47: 845-53. Doi: 10.1097/00005373-199911000-00004.

19. Feliciano DV. Management of penetrating injuries to carotid artery. World J Surg. 2001; 25: 1028-35. Doi: 10.1007/s00268-001-0055-y.

20. Herrera DA, Vargas SA, Dublin AB. Endovascular treatment of penetrating traumatic injuries of the extracranial carotid artery. J Vasc Interv Radiol. 2011; 22: 28-33. Doi: 10.1016/j.jvir.2010.09.022.

21. Blitzer DN, Ottochian M, O'Connor JV, Feliciano DV, Morrison JJ, DuBose JJ, et al. Timing of intervention may influence outcomes in blunt injury to the carotid artery. J Vasc Surg. 2020; 71: 1323-1332.e5. Doi: 10.1016/j.jvs.2019.05.059.

22. Serna C, Saldarriaga L, Folleco E, Rosero A, Caicedo Y, Timaran S, et al. La nueva realidad: manejo endovascular del trauma de carótida. Rev Colomb Cirugía 2021; 36(3): 421-426. Doi: 10.30944/20117582.832

23. Demetriades D, Asensio JA, Velmahos G, Thal E. Complex problems in penetrating neck trauma. Surg Clin North Am. 1996; 76: 661-83. Doi: 10.1016/S0039-6109(05)70475-8.

24. Navsaria P, Omoshoro-Jones J, Nicol A. An analysis of 32 surgically managed penetrating carotid artery injuries. Eur J Vasc Endovasc Surg. 2002; 24: 349-55. Doi: 10.1053/ejvs.2002.1736.

25. Ordoñez CA, Rodríguez F, Parra M, Herrera JP, Guzmán-Rodríguez M, Orlas C, et al. Resuscitative endovascular balloon of the aorta is feasible in penetrating chest trauma with major hemorrhage: Proposal of a new institutional deployment algorithm. J Trauma Acute Care Surg. 2020; 89: 311-9. Doi: 10.1097/ ta.0000000000002773.

26. Ordoñez CA, Rodríguez F, Orlas CP, Parra MW, Caicedo Y, Guzmán M, et al. The critical threshold value of systolic blood pressure for aortic occlusion in trauma patients in profound hemorrhagic shock. J Trauma Acute Care Surg. 2020; 89: 1107-13. Doi: 10.1097/TA.0000000000002935.

27. Feliciano DV. Penetrating cervical trauma. "current concepts in penetrating trauma", IATSIC Symposium, International Surgical Society, Helsinki, Finland, August 25-29, 2013. World J Surg. 2015; 39: 1363-72. Doi: 10.1007/s00268-014-2919-y.

28. Ditzel RM, Anderson JL, Eisenhart WJ, Rankin CJ, DeFeo DR, Oak S, et al. A review of transfusion- And trauma-induced hypocalcemia: Is it time to change the lethal triad to the lethal diamond? J Trauma Acute Care Surg. 2020; 88: 434-9. Doi: 10.1097/TA.0000000000002570. 
29. Narrod JA, Moore EE. Selective management of penetrating neck injuries. A prospective study. Arch Surg. 1984; 119(5): 574-8. doi: 10.1001/archsurg.1984.01390170070014.

30. White PW, Walker PF, Bozzay JD, Patel JA, Rasmussen TE, White JM. Management and outcomes of wartime cervical carotid artery injury. J Trauma Acute Care Surg. 2020; 89: S225-30. Doi: 10.1097/ TA.0000000000002755.

31. Watson JDB, Houston R 4th, Morrison JJ, Gifford SM, Rasmussen TE. A retrospective cohort comparison of expanded polytetrafluorethylene to autologous vein for vascular reconstruction in modern combat casualty care. Ann Vasc Surg. 2015; 29: 822-9. Doi: 10.1016/j.avsg.2014.12.026.

32. Mandeville Y, Canovai E, Diebels I, Suy R, De Vleeschauwer P. Carotid bifurcation resection and interposition of a polytetrafluorethylene graft (brig) for carotid disease: a retrospective study of 153 consecutive procedures. Ann Vasc Surg. 2015; 29: 1589-97. Doi: 10.1016/j.avsg.2015.05.025. 